Goldschmidt 2021 Abstract

https://doi.org/10.7185/gold2021.4160

\section{Physical shielding promotes long term preservation of DNA in lake sediments}

\author{
XINGGUO HAN ${ }^{1}$, JULIE TOLU ${ }^{1,2}$, LONGHUI DENG ${ }^{1}$, \\ ANNIKA FISKAL ${ }^{1,3}$, CARSTEN JOHNNY SCHUBERT ${ }^{1,4}$, \\ LENNY WINKEL $^{1,2}$ AND MARK ALEXANDER LEVER ${ }^{1}$ \\ ${ }^{1}$ ETH Zurich \\ ${ }^{2}$ Eawag, Swiss Federal Institute of Aquatic Science and \\ Technology \\ ${ }^{3}$ Federal Institute of Hydrology \\ ${ }^{4}$ Eawag
}

Presenting Author: mark.lever@usys.ethz.ch

Lake sediments are globally important organic carbon (OC) sinks. Previous studies have suggested that biomolecule chemical reactivity, adsorption and physical shielding to be important factors controlling OC degradation rates in sediments. Yet, the relative importance of these variables, and how OC from different organismal sources changes over time due to sourcedependent variations in degradation rates are still unclear in lake sediments.

Here we investigate the factors that control organic biomolecule degradation over several centuries based on a multiproxy approach targeting eukaryotic DNA, biomarkers, and organic macromolecule records in sediments of five lakes in central Switzerland that differ in trophic states. We specifically target biomolecules derived from sedimentary diatoms, green algae, and vascular plants. We show that the decay rates of diatom DNA are significantly higher than the decay rates of diatom lipid biomarkers, which is consistent with the expected higher chemical reactivity of DNA. Remarkably, the decay rates of green algal DNA and vascular plant DNA are much slower than those of diatom DNA and similar in magnitude to their corresponding membrane lipids and macromolecules (i.e., chlorophyll or lignin). In the case of vascular plant biomolecules (DNA and lignin), no significant biomolecule degradation was detected over time scales of 100-600 years.

Our results suggest that chemical reactivity and physical shielding, but not adsorption, are key variables controlling organic biomolecule decay in the lakes studied. In the case of green algae and vascular plants, physical shielding by degradation-resistant cell wall components appears to promote the long-term preservation of highly reactive biomolecules such as DNA. These findings have important implications for understanding the lacustrine sedimentary OC cycling and the use of sedimentary DNA to reconstruct past environmental changes.

Fig.1 Decay rates of DNA (black colors), biomarkers (blue colors), and macromolecules (pink colors) based on lakespecific averages. Error bars correspond to standard deviations. Averages and standard deviations were calculated based on slope values from the deepest station in each lake $(n=5)$. Significant differences between biomolecules were determined using a Wilcoxon Pairwise Rank Sum Test $(* \mathrm{P}<0.05)$. Diatom sterol: brassicasterol+24-methylenecholesterol, $\mathrm{C} 15+\mathrm{C} 17+\mathrm{C} 19$ : shortchain $n$-alkanes, $\mathrm{C} 14+\mathrm{C} 16+\mathrm{C} 18$ : short-chain fatty acids, $\mathrm{C} 20: 5 \mathrm{n} 3$ and C18:2n6: unsaturated fatty acids.

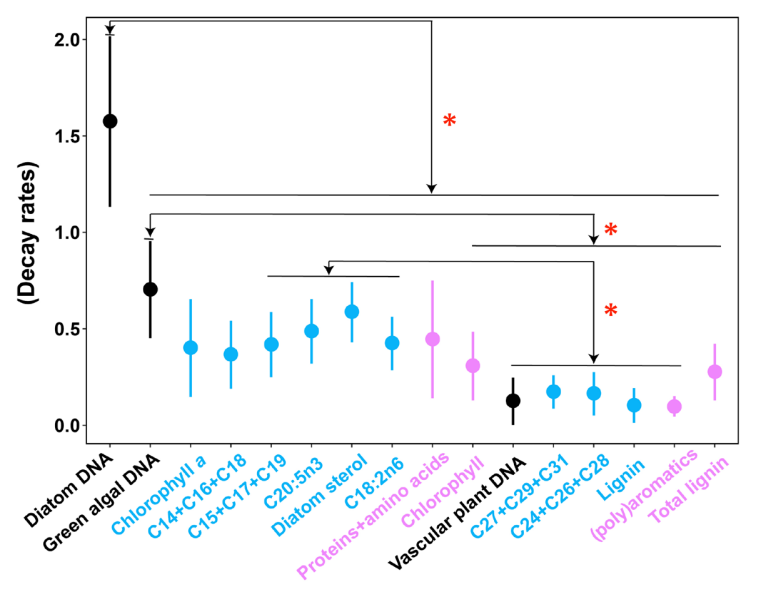

